\title{
BMJ Open Evaluating quality and its determinants in lipid control for secondary prevention of heart disease and stroke in primary care: a study in an inner London Borough
}

\author{
Hiten Dodhia, ${ }^{1}$ Liu Kun, ${ }^{2}$ Hugh Logan Ellis, ${ }^{3}$ James Crompton, ${ }^{1}$ \\ Anthony S Wierzbicki, ${ }^{4}$ Helen Williams, ${ }^{5}$ Anna Hodgkinson, ${ }^{6}$ John Balazs ${ }^{7}$
}

To cite: Dodhia $\mathrm{H}$, Kun L, Logan Ellis $\mathrm{H}$, et al.

Evaluating quality and its determinants in lipid control for secondary prevention of heart disease and stroke in primary care: a study in an inner London Borough. BMJ Open 2015;5:e008678. doi:10.1136/bmjopen-2015008678

- Prepublication history and additional material is available. To view please visit the journal (http://dx.doi.org/ 10.1136/bmjopen-2015008678).

Received 6 May 2015 Revised 3 October 2015 Accepted 16 October 2015

CrossMark

For numbered affiliations see end of article.

\section{Correspondence to}

Dr Hiten Dodhia;

hiten.dodhia@southwark.gov. uk

\section{ABSTRACT}

Objectives: To assess quality of management and determinants in lipid control for secondary prevention of cardiovascular disease (CVD) using multilevel regression models.

Design: Cross-sectional study.

Setting: Inner London borough, with a primary care registered population of 378000 (2013).

Participants: $48 / 49$ participating general practices with 7869 patients on heart disease/stroke registers were included.

Outcome measures: (1) Recording of current total cholesterol levels and lipid control according to national evidence-based standards. (2) Assessment of quality by age, sex, ethnicity, deprivation, presence of other risks or comorbidity in meeting both lipid measurement and control standards.

Results: Some process standards were not met. Patients with a current cholesterol measurement $>5 \mathrm{mmol} / \mathrm{L}$ were less likely to have a current statin prescription (adjusted OR=3.10; 95\% Cl 2.70 to 3.56 ). They were more likely to have clustering of other CVD risk factors. Women were significantly more likely to have raised cholesterol after adjustment for other factors (adjusted OR=1.74; 95\% Cl 1.53 to 1.98).

Conclusions: In this study, the key factor that explained poor lipid control in people with CVD was having no current prescription record of a statin. Women were more likely to have poorly controlled cholesterol (independent of comorbid risk factors and after adjusting for age, ethnicity, deprivation index and practice-level variation). Women with CVD should be offered statin prescription and may require higher statin dosage for improved control.

\section{INTRODUCTION}

Hyperlipidaemia contributes a significant proportion of modifiable cardiovascular disease (CVD) risk. ${ }^{1}$ Most of the CVD risk attributable to lipids is due to lipoprotein

\section{Strengths and limitations of this study}

- This is a large study using epidemiological design and multilevel regression modelling to identify determinants in management of lipid control using routine data.

- We used a systematic approach that can be used by Clinical Commissioning Groups to meet their duty to understand and reduce variation in access and outcomes to healthcare.

- There may be potential measurement errors/ biases and the data did not include date of any original cardiovascular disease event;

- The findings from this study may not be generalisable to rest of UK.

particles associated with cholesterol deposition in the vascular wall including total cholesterol, non-high-density lipoprotein cholesterol (HDL-C) and low-density lipoprotein cholesterol (LDL-C). ${ }^{2}$ Interventions that reduce $\mathrm{LDL}-\mathrm{C}$ reduce CVD risk with a relationship from clinical trials that show a $21 \%$ relative risk reduction in major vascular events per $1 \mathrm{mmol} / \mathrm{L}$ reduction in LDL-C in all groups. ${ }^{3}$

The National Institute for Health and Care Excellence (NICE) lipid modification guidelines (CG67 2008 and updated CG181, 2014) advise clinicians to offer statins to all individuals with increased risk of CVD as determined by a QRISK2 or Framingham (1991)-based CVD risk score of $20 \%$ over the next decade. ${ }^{4-6}$ These risk calculation tools give similar results but Framingham overpredicts CVD in UK populations. ${ }^{7}$ Statin treatment is to be prescribed to all patients with established CVD using simvastatin $40 \mathrm{mg}$ in most patients and atorvastatin $80 \mathrm{mg}$ in acute coronary syndromes. NICE guideline advises 
that cholesterol is checked within 3 months of starting a statin with the aim that patients with established CVD should ideally reach total cholesterol $<4 \mathrm{mmol} / \mathrm{L}$; LDL-C $<2 \mathrm{mmol} / \mathrm{L}$ with an audit standards of total cholesterol $<5 \mathrm{mmol} / \mathrm{L}$ and LDL-C $<3 \mathrm{mmol} / \mathrm{L} .{ }^{6}$ In primary prevention, no target is specified but all should be treated with simvastatin $40 \mathrm{mg}$ or another off-patent agent of similar efficacy. ${ }^{8}$

General practitioners (GPs) are currently incentivised to manage CVD by the Quality and Outcomes Framework (QOF) which is a 'Pay for Performance' (P4P) system. The QOF control target in 2012-2013 was total cholesterol of $<5 \mathrm{mmol} / \mathrm{L} .{ }^{9}$ There is some evidence that $\mathrm{P} 4 \mathrm{P}$ can improve quality of care, but this evidence is not strong and other factors are also likely to play a role. ${ }^{10}{ }^{11}$ In addition, the EUROASPIRE III survey has shown that evidence-based guideline targets for lifestyle, risk factors and drug treatments are not being achieved and there remains considerable potential to raise standards to prevent further events and that statins are suboptimally used. ${ }^{12}{ }^{13}$ Inequalities in the management of CVD in primary care have been reported previously with key sex inequalities between men and women and ethnic inequalities. ${ }^{14} 15$

The Health and Social Care Act 2012 in the UK places a duty on Clinical Commissioning Groups to improve quality and reduce inequalities in access and outcomes of care. ${ }^{1617}$ Our aim was to evaluate the quality in the management of cholesterol for the secondary prevention of CVD in Lambeth patients on the coronary heart disease (CHD) and/or stroke registers. We compared lipid measurement and control to predefined standards based on QOF and NICE guidelines. ${ }^{6}{ }^{18}$ We also evaluated the determinants in the management of lipid control and hypothesised that there should be no group differences in the management and control of cholesterol in this cohort of patients on the above registers, according to the predefined standards.

\section{METHODS}

This evaluation was carried out in an inner city London borough, with a registered population of 378000 (2013). We used a cross-sectional study design and identified those patients who were on the CHD and/or stroke registers as of 31 March 2013 and the period 15 months prior to this date.

We used patient-level data from the Lambeth DataNet. This is a pseudo-anonymised database of patients registered with practices in primary care that supports local commissioning, healthcare/service evaluation and monitoring health inequalities. We identified people registered on the CHD and/or stroke registers from 48 of 49 practices that contribute data to the Lambeth DataNet. A key purpose of this database is also to collect and analyse markers of health inequalities such as ethnicity, index of multiple deprivation (IMD), as well as age and sex. The IMD includes income deprivation; employment deprivation; health deprivation and disability; education deprivation; and other markers of deprivations such as crime, barriers to housing and services, and the living environment.

\section{Predefined standards}

The standards that were used to assess the quality of care were a combination of the upper range of the QOF 12-13 and NICE guidelines. ${ }^{69}$

\section{Coronary heart disease}

- Cholesterol level is measured in the past 15 months (at or prior to 31 March 2013) in 90\% (range 50-90\%) of all patients on the CHD register;

- Cholesterol control $\leq 5 \mathrm{mmol} / \mathrm{L}$ in $70 \%$ (range 45-70\%) of all patients on CHD register.

\section{Stroke}

- Cholesterol level measured in the past 15 months (at or prior to 31 March 2013) in 90\% (range 50-90\%) of all patients on the stroke register;

- Cholesterol $\leq 5 \mathrm{mmol} / \mathrm{L}$ in $65 \%$ (range $40-65 \%$ ) of all patients on stroke register.

We also analysed data on the current prescription of statins for this cohort of patients within the past 3 months from their last review date. NICE guidelines recommend that all patients with heart disease or stroke should be prescribed a statin or have reasons recorded if not prescribed.

\section{Hypothesis tested}

The hypotheses we were testing were as follows:

1. Patients in Lambeth with one or more diagnoses of CHD and stroke are managed according to the predefined quality standards for cholesterol for people on these two registers as of 2012/2013.

2. In Lambeth patients with one or more diagnoses of CHD and stroke-there are no significant group differences as assessed by age, sex, ethnicity, deprivation, presence of other risks or comorbidity in meeting these predefined quality standards.

\section{Analysis}

We used STATA V.13.1 to test the hypotheses. ${ }^{19}$ Descriptive analyses were done to test the first hypothesis. The outcome (dependent) variables for the regression models were dichotomous and were defined above in the 'predefined standards' section. They include (1) measurement of cholesterol (DO1-yes/no) and (2) total cholesterol $\leq 5 \mathrm{mmol} / \mathrm{L}$ (DO2-as controlled and $>5 \mathrm{mmol} / \mathrm{L}$ as uncontrolled).

The presence of group differences (independent variables) in these were reviewed by: age group (16-44, 45-54, 55-64, 65-74 and $\geq 75$ ), sex (male, female), ethnic groups (white group, black African/black Caribbean/ black British group, missing/unknown, Asian/ Asian-British group, mixed group, other ethnic group), IMD quintiles (grouped as follows: least deprived two quintiles $0-40 \%, 40-60 \%, 60-80 \%$; most deprived 
$80-100 \%$ ), as well as risk factors for smoking (current smokers, ex-smokers, non-smokers and unknown) and blood pressure or BP (controlled defined as $\mathrm{BP} \leq 150 / 90$; uncontrolled defined as BP $>150 / 90)$, type 2 diabetes status (yes or no) and statin prescription status within time frame described above (yes or no).

A number of univariate multilevel logistic regression models taking into account the variation among different general practices were fitted to explore the associations between the outcome variable and different independent variables tested in the second hypothesis. Then a series of multivariate multilevel logistic regression models were fitted to investigate the associations between the predefined standards and all potential independent variables, using random-effect equation for the practice-level variation. Best and final models chosen by series of Wald goodness-of-fit tests were reported in the Results section. ${ }^{20}$

\section{RESULTS}

The total number of primary care practices that participated was 48/49 (98\%). The number of people on the CHD and stroke registers was 7869 (CHD only: 4464; stroke only: 2738; combined $\mathrm{CHD} /$ stroke $=667$ ). The diagnosed crude prevalence of $\mathrm{CHD}$ and stroke were $1.3 \%$ and $0.9 \%$, respectively, in Lambeth in 2012$2013 .{ }^{18}$ The mean age was 69.8 years $(95 \%$ confidence limits 69.5 to 70.1 ). There were significantly more males on the registers: male $57.8 \%$ (56.7\% to $58.9 \%$ ) compared with female $42.2 \%$ (41.1\% to $43.3 \%)$. Other demographic characteristics are shown in table 1.

Table 2 shows the risk factor characteristics. In this population, about $19 \%$ of people with CHD or stroke remained current smokers, just over one in four were not controlled for their blood pressure to a level of 150 / $90 \mathrm{~mm} \mathrm{Hg}$ and $70 \%$ were overweight or obese. Just over one in four had type 2 diabetes.

Hypothesis 1: Patients with one or more of CHD and stroke are managed according to predefined standards for cholesterol measurement and control for people on these two registers as of 2012/2013 and 2013/2014.

Table 3 shows the evaluation of patients having a current record for cholesterol measurement, degree of cholesterol control achieved and a record of a statin prescription. Overall, predefined auditable standards were not met for current records for both cholesterol measurement and statin prescription. However, predefined auditable standards for those patients with a current record, the proportion of patients whose cholesterol was below $5 \mathrm{mmol} / \mathrm{L}$ were met. When comparing subgroups within the study, patients with a history of stroke were consistently the least likely to meet all three QOF standards.

Primary care records showed that overall $80.1 \%$ of patients had been prescribed a statin in the past 6 months. This rate was significantly lower in patients with stroke.

Hypothesis 2: In patients with one or more of CHD and stroke-there are no significant group differences in the

\begin{tabular}{|c|c|c|c|}
\hline $\begin{array}{l}\text { Demographic } \\
\text { characteristics }\end{array}$ & Sublevel & $\begin{array}{l}\text { Number } \\
(n=7869)\end{array}$ & $\begin{array}{l}\text { Per } \\
\text { cent }\end{array}$ \\
\hline \multirow[t]{6}{*}{ Age } & $16-44$ & 333 & 4.2 \\
\hline & $45-54$ & 840 & 10.7 \\
\hline & $55-64$ & 1340 & 17.0 \\
\hline & $65-74$ & 2035 & 25.9 \\
\hline & $\geq 75$ & 3293 & 41.9 \\
\hline & Unknown & 28 & 0.4 \\
\hline \multirow[t]{2}{*}{ Sex } & Male & 4547 & 57.8 \\
\hline & Female & 3322 & 42.2 \\
\hline \multirow[t]{6}{*}{ Ethnicity } & White group & 4361 & 55.4 \\
\hline & Black/black & 1616 & 20.5 \\
\hline & $\begin{array}{l}\text { Asian/ } \\
\text { Asian-British } \\
\text { group }\end{array}$ & 694 & 8.8 \\
\hline & Mixed group & 212 & 2.7 \\
\hline & $\begin{array}{l}\text { Other ethnic } \\
\text { group }\end{array}$ & 193 & 2.5 \\
\hline & $\begin{array}{l}\text { Missing/ } \\
\text { unknown }\end{array}$ & 793 & 10.1 \\
\hline \multirow{5}{*}{$\begin{array}{l}\text { Index of } \\
\text { deprivation }\end{array}$} & Least deprived & 195 & 2.5 \\
\hline & $40-60 \%$ & 976 & 12.4 \\
\hline & $60-80 \%$ & 3816 & 48.5 \\
\hline & $\begin{array}{l}\text { Most deprived } \\
80-100 \%\end{array}$ & 2837 & 36.1 \\
\hline & Missing & 45 & 0.6 \\
\hline
\end{tabular}

outcome (dependent) variables DO1 and DO2 as assessed by age, sex, ethnicity and deprivation in meeting the predefined standards.

We found significant group differences in meeting the lipid measurement standards. Table 4 shows the findings for patients who did not have a current record of cholesterol measurement in the past 15 months. The random effect at the general practice level is reported at the

\begin{tabular}{llrr} 
Table 2 & Risk factor characteristics & & \\
\hline Risk factor & Sublevel & Number & Per cent \\
\hline Smoking* $^{*}$ & Non-smoker & 4146 & 52.7 \\
& Current smoker & 1456 & 18.5 \\
& Ex-smoker & 2191 & 27.8 \\
& Unknown & 76 & 1.0 \\
BP $^{*}$ & BP $\leq 150 / 90$ & 5604 & 71.2 \\
& BP $>150 / 90$ & 2182 & 27.7 \\
& Missing & 83 & 1.1 \\
Body mass index $†$ & $<18.5$ & 138 & 1.9 \\
& $18.5-24.9$ & 1999 & 27.8 \\
& $25-29.9$ & 2613 & 36.4 \\
& $30-39.9$ & 2164 & 30.1 \\
& $\geq 40$ & 267 & 3.7 \\
Type 2 diabetes ${ }^{*}$ & Yes & 2104 & 26.3 \\
& No & 5765 & 73.3 \\
\hline${ }^{*} n=7869$. & & & \\
$\dagger n=7181$. & & & \\
BP, blood pressure. & &
\end{tabular}


Table 3 Evaluation against standards

\begin{tabular}{|c|c|c|c|c|c|}
\hline \multirow[b]{2}{*}{ Register } & \multirow[b]{2}{*}{ Number } & \multirow[b]{2}{*}{ Per cent } & \multicolumn{2}{|c|}{ 95\% confidence limits } & \multirow[b]{2}{*}{ Standard (\%) } \\
\hline & & & Lower limit & Upper limit & \\
\hline \multicolumn{6}{|c|}{ Current record in the past 15 months } \\
\hline Stroke only & 2284 & 83.4 & 82.0 & 84.8 & 90 \\
\hline CHD only & 3831 & 85.8 & 84.8 & 86.8 & 90 \\
\hline CHD and stroke & 597 & 89.5 & 86.9 & 91.7 & 90 \\
\hline \multicolumn{6}{|c|}{ Cholesterol $\leq 5 \mathrm{mmol} / \mathrm{L}$ with current record in the past 15 months } \\
\hline Stroke only & 1716 & 75.1 & 73.3 & 76.9 & 65 \\
\hline CHD only & 3114 & 81.3 & 80.0 & 82.5 & 70 \\
\hline Stroke and CHD & 505 & 84.6 & 81.4 & 87.4 & 70 \\
\hline \multicolumn{6}{|c|}{ Statin prescription recorded in the past 6 months and current record in the past 15 months } \\
\hline Stroke only & 1630 & 71.4 & 69.5 & 73.2 & 100 \\
\hline CHD only & 3203 & 83.6 & 82.4 & 84.8 & 100 \\
\hline Stroke and CHD & 511 & 85.6 & 82.5 & 88.3 & 100 \\
\hline
\end{tabular}

bottom of the table. The variance component was estimated to be 0.12. Patients categorised as African-American/black British group (compared with the white group) were significantly more likely to have a current record, as were patients with type 2 diabetes (compared with people without type 2 diabetes). Patients aged between 16 and 64 years or over 75 years were significantly less likely to have a current record for cholesterol levels. Patients aged 16-44 were 68\% more likely to not have a current record compared with those aged 65-74. After taking into account other factors, deprivation did not appear to have an effect on current cholesterol recording. Those who were current smokers and had previously raised cholesterol level were also less likely to have a current record of cholesterol level.

Patients with no current record for cholesterol in the past 15 months were nearly three times less likely (adjusted odds=2.97; 95\% CI 2.51 to 3.52 ) to have a record of a current statin prescription.

Table 5 shows the finding for the subgroup of patients who had a current record of cholesterol but were not achieving a lipid control standards (cholesterol level $<5 \mathrm{mmol} / \mathrm{L}$ ) within the past 15 months of the study date. The random effect at the general practice level is reported at the bottom of the table. The variance component was estimated to be 0.022 . These patients were significantly more (OR $3.10 ; 95 \%$ CI 2.70 to 3.56 ) likely not to have a current record for a statin prescription. After adjustment for other factors, they were also more likely to be current smokers and to have raised blood pressure. Women were also significantly more likely than men to have raised cholesterol after adjustment for other factors. Women were significantly less likely to have a current record for a statin prescription $(75 \%$; $74 \%$ to $77 \%)$ compared with men $(83 \%$; $82 \%$ to $84 \%)$. There were significant differences in current recorded prescribing with age (those aged 16-44 and 45-54 were less likely to have a current record of statins prescribed: $44 \%$ and $71 \%$, respectively) and ethnicity (African-American/black British groups were less likely to have statins prescribed and Asian groups more likely: $74 \%$ and $88 \%$, respectively). However, there was no significant difference in the adjusted OR with age (apart from the $75+$ age group who were significantly better controlled) and ethnicity for poor lipid control. Patients with additional comorbidity with type 2 diabetes were significantly more likely to achieve cholesterol control $<5 \mathrm{mmol} / \mathrm{L}$.

\section{DISCUSSION}

\section{Key findings}

In this study of patients attending primary care practices in an inner London borough in South London, the key factor that explained poor lipid control in people on the CHD and stroke registers was having no record of having been prescribed a statin in the past 3 months from their last review date. Women were less likely to be prescribed a statin compared with men. Among individuals with previous history of CHD or stroke, women are more likely than men to have poorly controlled cholesterol. This finding was independent of smoking status, blood pressure, statin prescription and type 2 diabetes status and also remained unchanged after adjusting for age, ethnicity, deprivation index and practice-level variation. We found no ethnic difference in lipid control after adjustment for other factors. The very elderly $(75+)$ were significantly better controlled.

Patients with a history of both CHD and stroke were those most likely to be managed according to current guidelines. Patients who had only had a stroke were less likely to have had their cholesterol measured, controlled or to be prescribed a statin than patients with CHD.

There was a clustering of risk factors in that patients who had poor lipid control were also more likely to be current smokers, have raised blood pressure and were less likely to have a current statin prescription recorded.

\section{What is already known}

Studies looking at the efficacy of lipid-lowering treatments in patients with established CVD have found no 
Table 4 Multilevel logistic regression model—current record for measurement of cholesterol (DO1) in the past 15 months and demographic, risk factor and treatment with statin characteristics

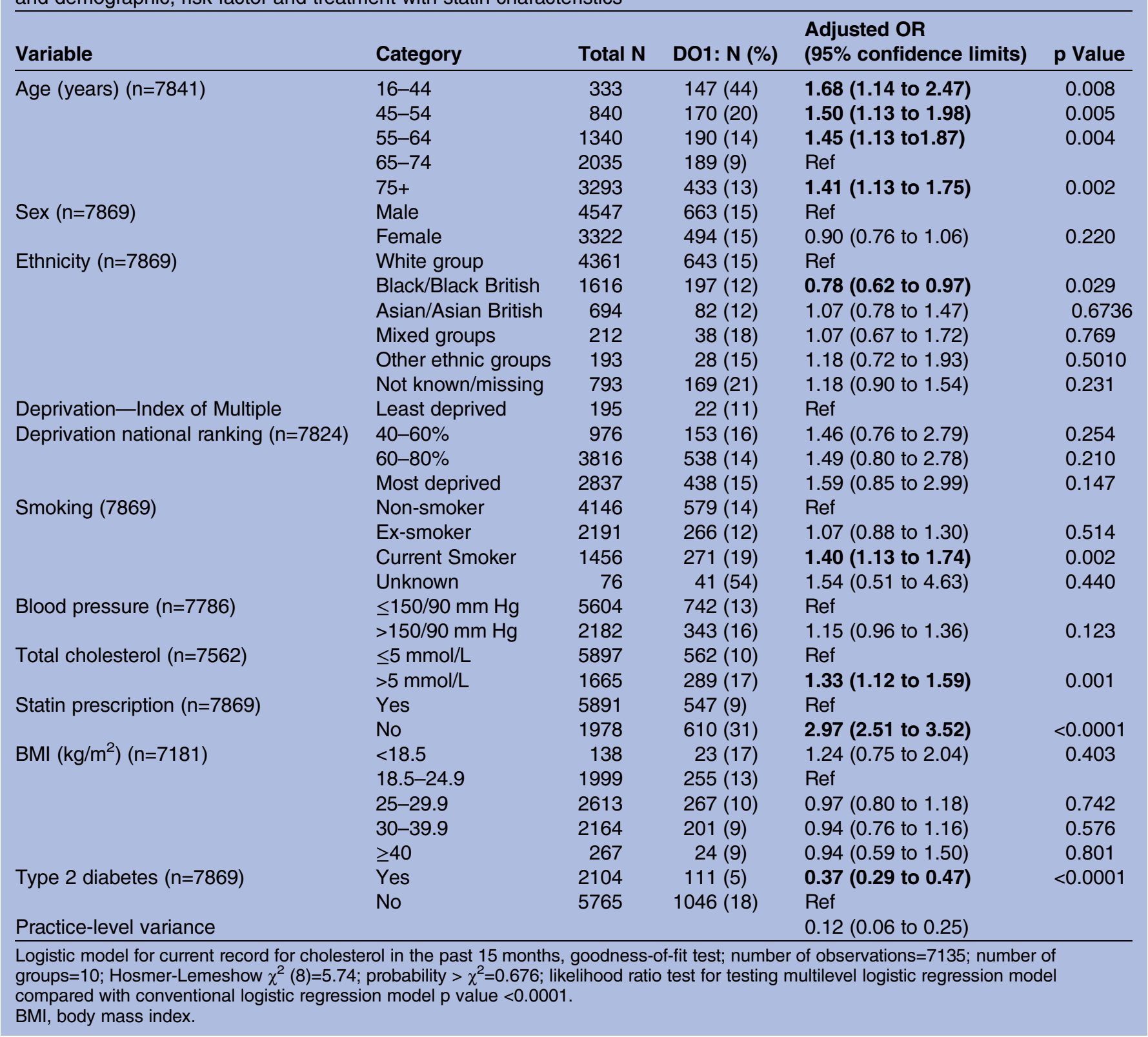

significant differences between sexes but found that women were more likely than men to have higher LDL-C levels both before and after treatment suggesting that women may need more aggressive lipid-lowering treatment than men to achieve targets. ${ }^{14} 21-25$

Women are less likely to be prescribed medication including statins as secondary prevention following stroke $^{26} 27$ and acute coronary syndrome. ${ }^{28}$ These findings are true internationally with similar results being found in Ireland, ${ }^{29}$ Italy ${ }^{30}$ and Sweden..$^{31}$ Large studies suggest that the effect is mainly seen in younger women. ${ }^{32}{ }^{33}$ Similar results have previously been found in East London. ${ }^{34}$ Women were also less likely to be prescribed aggressive lipid-lowering treatment or any treatment at all. A Canadian study also found discrepancies between the three groups: stroke, CHD and both, as well as sex discrepancies similar to the results found in Lambeth. ${ }^{35}$ Some studies have failed to find a significant difference in lipid treatment between the sexes. ${ }^{36}{ }^{37}$ Others suggest that sex differences disappear once the data have been adjusted for age and severity of disease. ${ }^{38} 39$ Millett et al in their study identified improvements in lipid control and blood pressure targets in ethnic groups, although black groups were less likely to be prescribed statins. They suggested that the introduction of QOF led to marked improvements in both the process of care and management of CHD. They did not report on sex or age differences in lipid control. ${ }^{15}$ A systematic review of 27 studies looking at equity dimensions in the evaluation of QOF, across a 
Table 5 Multilevel logistic regression model-total cholesterol level $>5 \mathrm{mmol} / \mathrm{L}$ (DO2) in the past 15 months

\begin{tabular}{|c|c|c|c|c|c|}
\hline Variable & Category & Total N & DO2: N (\%) & $\begin{array}{l}\text { Adjusted OR } \\
\text { (95\% confidence limits) }\end{array}$ & p Value \\
\hline \multirow[t]{5}{*}{ Age $(n=6711)$} & $16-44$ & 186 & $49(26)$ & $0.79(0.54$ to 1.14$)$ & 0.208 \\
\hline & $45-54$ & 670 & $186(28)$ & 1.20 (0.96 to 1.50$)$ & 0.102 \\
\hline & $55-64$ & 1149 & $261(23)$ & 1.10 (0.91 to 1.33$)$ & 0.330 \\
\hline & $65-74$ & 1846 & $380(21)$ & Ref & \\
\hline & $75+$ & 2860 & $500(17)$ & 0.74 (0.63 to 0.88$)$ & $<0.0001$ \\
\hline \multirow[t]{2}{*}{$\operatorname{Sex}(n=6711)$} & Male & 3883 & 649 (17) & Ref & \\
\hline & Female & 2828 & $727(26)$ & 1.74 (1.53 to 1.98$)$ & $<0.0001$ \\
\hline \multirow[t]{6}{*}{ Ethnicity $(n=6711)$} & White group & 3717 & $762(21)$ & Ref & \\
\hline & Black/Black British & 1419 & $310(22)$ & 0.99 (0.84 to 1.16$)$ & 0.892 \\
\hline & Asian/Asian British & 612 & $90(15)$ & 0.85 (0.66 to 1.09$)$ & 0.198 \\
\hline & Mixed groups & 174 & $41(24)$ & 1.04 (0.71 to 1.54$)$ & 0.830 \\
\hline & Other ethnic groups & 165 & $29(18)$ & 0.85 (0.56 to 1.31$)$ & 0.470 \\
\hline & Not known/missing & 624 & $144(23)$ & 1.13 (0.91 to 1.40$)$ & 0.264 \\
\hline Deprivation (Index of Multiple & Least deprived & 173 & $37(21)$ & Ref & \\
\hline \multirow[t]{3}{*}{ Deprivation national ranking) $(n=6672)$} & $40-60 \%$ & 822 & $148(18)$ & 0.79 (0.52 to 1.21$)$ & 0.276 \\
\hline & $60-80 \%$ & 3278 & $677(21)$ & 0.91 (0.61 to 1.35$)$ & 0.634 \\
\hline & Most deprived & 2399 & $508(21)$ & 0.91 (0.61 to 1.37$)$ & 0.664 \\
\hline \multirow[t]{4}{*}{ Smoking $(\mathrm{n}=6711)$} & Non-smoker & 3566 & $736(21)$ & Ref & \\
\hline & Ex-smoker & 1925 & $346(18)$ & 1.00 (0.86 to 1.18$)$ & 0.939 \\
\hline & Current Smoker & 1185 & $286(24)$ & 1.28 (1.07 to 1.52$)$ & 0.006 \\
\hline & Unknown & 35 & $8(23)$ & $1.33(0.57$ to 3.11$)$ & 0.506 \\
\hline \multirow[t]{2}{*}{ Blood pressure $(n=6700)$} & $\leq 150 / 90 \mathrm{~mm} \mathrm{Hg}$ & 4861 & $898(18)$ & Ref & \\
\hline & $>150 / 90 \mathrm{~mm} \mathrm{Hg}$ & 1839 & $477(26)$ & 1.35 (1.17 to 1.54$)$ & $<0.0001$ \\
\hline \multirow[t]{2}{*}{ Statin prescription $(n=6711)$} & Yes & 5344 & $845(16)$ & Ref & \\
\hline & No & 1367 & 531 (39) & $3.10(2.70$ to 3.56$)$ & $<0.0001$ \\
\hline \multirow[t]{2}{*}{ Type 2 diabetes $(n=6711)$} & Yes & 1993 & $1098(23)$ & 0.62 (0.53 to 0.72$)$ & $<0.0001$ \\
\hline & No & 4718 & $278(14)$ & & \\
\hline Practice-level variance & & & & $0.022(0.005$ to 0.095$)$ & \\
\hline
\end{tabular}

Logistic model for total cholesterol level $>5 \mathrm{mmol} / \mathrm{L}$ in the past 15 months, goodness-of-fit test number of observations $=6370$; number of groups $=10$; Hosmer-Lemeshow $\chi^{2}(8)=16.26$; probability $>\chi^{2}=0.039$; likelihood ratio test for testing multilevel logistic regression model compared with conventional logistic regression model $p$ value $=0.045$.

range of conditions, did not suggest worsening inequity in treatment or treatment outcomes. ${ }^{40}$

\section{What this paper adds}

The Health and Social Care Act 2012 places a duty on Clinical Commissioning Groups to reduce inequalities in access and outcomes of care. ${ }^{16}$ This paper shows that routine pseudo-anonymised patient-level data can be used to monitor quality and its determinants in a systematic way. We found important age differences in the processes of care-people aged 16-64 were less likely to meet lipid measurement standards. Lack of cholesterol measurement may be a proxy to access care. Possible explanations for these age differences need further exploration but could be related to higher risk taking behaviour in younger age groups, more reluctance to take time off work and attend routine healthcare leading to lower access to care in this age group. Patients from black ethnic groups and with comorbidity with diabetes were more likely to meet the lipid measurement standard. Possible explanations for this may be better systems in place for people with comorbidities or that they are more likely to attend or be followed up for care processes.
For the lipid control standards, the findings of this study in South London are similar to those observed worldwide. In patients with established CVD population, women are more likely than men to have raised cholesterol, and yet they are less likely to be prescribed a statin. Critically patients with poor lipid control were also significantly less likely to have a current statin prescription record. Possible explanation for these findings need further exploration but could include (1) the majority of women in this area live in more deprived circumstances which may lead to lower health literacy and lower level of clinical engagement; (2) women may see themselves as lower risk of CVD and can be mistakenly perceived as being at lower risk by clinicians. However, patients with diabetes (as an additional comorbidity) were more likely to meet lipid control standards. Possible explanations for this are that additional comorbidity may lead to better systems of care provided by primary care. We believe that the methodology used in this paper provides an approach for evaluating determinants of quality of care that partly fit into the theory-based framework for conceptualising equity of care developed by Boeckxstaens et $a l^{40}$ We have outlined some of the limitations to our 
approach below. We have also provided online supplementary data tables that show improvements overall in recording of total cholesterol, current statin prescription and change in mean total cholesterol by age, sex, ethnicity and deprivation for the cohort of patients that had records in 2013 and 2011. These online supplementary data suggest that $\mathrm{P} 4 \mathrm{P}$ is continuing to have a positive impact locally but also shows differential changes in total cholesterol control by some of the characteristics we have reported.

\section{Limitations}

In the UK, all diagnosed cases of CHD and stroke are registered by GPs as part of QOF disease registers as this is part of the GP contract. We know from modelled estimates that the registers may underestimate actual number of cases by as much as $50 \%$-however, these estimates are based on a number of assumptions and there is uncertainty in modelled prevalence estimates. ${ }^{41}$ It would be important to understand the characteristics of people who may not be registered on the CHD/ stroke registers to understand equity of access to care more completely. This study used data from all cases that were diagnosed and on the QOF registers from all but one practice. There was a small proportion of data that was missing in the age, deprivation and some of the risk factors in the disease register. This varied for different indicators-for example, missing age was 28 records or $0.4 \%$ of all records; IMD 45 records or $0.6 \%$ of all records; cholesterol level recorded-this was 307 records or $4 \%$ of all records; body mass index was 688 records or $9 \%$ of all records; for the second outcome cholesterol level $>5 \mathrm{mmol}$ missing data were: IMD 39 records or $0.6 \%$ and 1 record for cholesterol level. However, as this was a large study, we do not think this will have introduced substantial non-response biases. This study used data collected from routine practice consultations, so there could be potential measurement errors or biases introduced as part of this. The data gathered did not include the date of any original CVD event and this factor was not considered in the regression analysis. Registry studies show a decline in adherence with cardiovascular preventive therapies including statins with time postevent. ${ }^{9}{ }^{12}$ The data gathered in this study do not allow differentiation of haemorrhagic from ischaemic strokes which may explain some of the differences in prescriptions. However, it is likely that most strokes were ischaemic in aetiology in this population. We also did not assess whether there was a record of prescriptions for other lipid-lowering strategies in this cohort, though statins are the most commonly prescribed lipid-lowering drugs there is substantial usage of ezetimibe in some areas in the UK. ${ }^{42}$ The data obtained did not include reasons for why women are not being prescribed statins, for example, whether they were declining them when offered, or whether they were experiencing more side effects and asking to stop taking statins or whether they were not being offered statins in the first place. We also were not able to explore whether healthcare professionals have a perception that women are lower risk of further CVD and not treated as aggressively as men. This study was conducted in a single setting and the findings may not be more widely generalisable to the UK population as implementation of NICE guidelines may vary in different areas. However, some of these results on lipid control outcomes are consistent with findings from other studies. These factors need further exploration to inform future strategies.

\section{CONCLUSIONS}

This evaluation has identified important quality issues and their determinants. Some of these variations in quality suggest possible health inequities in the secondary prevention of heart disease and stroke. The findings suggests that primary care has an important role in identifying and optimising management in those patients with CVD who do not have current record of cholesterol reading. GPs should also identify people with established CVD who have no current record of statin prescription as these patients had a greater probability of poor lipid control. This evaluation identified these patients were also more likely to have other CVD risks (raised blood pressure and current smokers). Finally, this study suggests that primary care professionals need to identify and optimise lipid management in patients with CVD who have no current statin prescription and also that women with CVD may require higher statin dosage for better lipid control for secondary prevention. Potential policy implications for $\mathrm{P} 4 \mathrm{P}$ systems such as QOF are that these need to consider the determinants of quality and the variation in implementation by social characteristics within a broader framework of equity of access, treatment and treatment outcomes based on an assessment of needs. ${ }^{40}$

\section{Author affiliations}

${ }^{1}$ Lambeth \& Southwark Councils, Public Health, London, UK

${ }^{2}$ Division of Health and Social Care Research, King's College London, London, UK

${ }^{3}$ Kings College NHS Foundation Trust, F2 Doctor, London, UK

${ }^{4}$ Department of Chemical Pathology, St Thomas' NHS Foundation Trust, London, UK

${ }^{5}$ NHS Southwark Clinical Commissioning Group, Medicines Management Team, London UK

${ }^{6}$ NHS Lambeth Clinical Commissioning Group, Medicines Management Team, London, UK

${ }^{7}$ NHS Lambeth Clinical Commissioning Group, Governing Body Member, London, UK

Contributors $\mathrm{HD}$ and $\mathrm{JC}$ designed the study. JC extracted and cleaned the data from Lambeth DataNet and HD and JC performed the primary analyses. $\mathrm{KL}$ and $\mathrm{HD}$ performed the logistic regression analyses and $\mathrm{KL}$ performed the multilevel logistic regression analyses. HLE reviewed the literature. HD and HLE drafted the manuscript and AW, HW, AH and JB critically edited the manuscript and provided final approval. $\mathrm{HD}$ is guarantor of this work and had full access to all the data in the study and takes responsibility for the integrity of the data and the accuracy of the data analysis.

Funding This research received no specific grant from any funding agency in the public, commercial or not-for-profit sectors. 
Competing interests ASW was the Chair of Lipids Guideline Group (CG181) (2013-2014) and a member of the Post-MI and Lipids Quality Standards Committee (2014). No other authors declared any competing interests.

Disclaimer The views expressed are those of the authors and not necessarily those of the NHS, the National Institute for Health Research, or the Department of Health.

Provenance and peer review Not commissioned; externally peer reviewed.

Data sharing statement No additional data are available.

Open Access This is an Open Access article distributed in accordance with the Creative Commons Attribution Non Commercial (CC BY-NC 4.0) license, which permits others to distribute, remix, adapt, build upon this work noncommercially, and license their derivative works on different terms, provided the original work is properly cited and the use is non-commercial. See: http:// creativecommons.org/licenses/by-nc/4.0/

\section{REFERENCES}

1. Yusuf S, Hawken S, Ounpuu S, et al. Effect of potentially modifiable risk factors associated with myocardial infarction in 52 countries (the INTERHEART study): case-control study. Lancet 2004;364:937-52.

2. Di Angelantonio E, Sarwar N, Perry P, et al., The Emerging Risk Factors Collaboration. Major lipids, apolipoproteins, and risk of vascular disease. JAMA 2009;302:1993-2000.

3. Baigent C, Blackwell L, Emberson J, et al., Cholesterol Treatment Trialists' (CTT) Collaboration. Efficacy and safety of more intensive lowering of LDL cholesterol: a meta-analysis of data from 170,000 participants in 26 randomised trials. Lancet 2010;376:1670-81.

4. Anderson KM, Odell PM, Wilson PW, et al. Cardiovascular disease risk profiles. Am Heart J 1991;121:293-8.

5. Hippisley-Cox J, Coupland C, Vinogradova Y, et al. Predicting cardiovascular risk in England and Wales: prospective derivation and validation of QRISK2. BMJ 2008;336:1475-82.

6. National Clinical Guideline Centre. Lipid modification: cardiovascula risk assessment and the modification of blood lipids for the primary and secondary prevention of cardiovascular disease CG67 (2008) \& CG181 (2014). London: National Institute of Health and Clinical Excellence, 2014

7. Collins GS, Altman DG. An independent external validation and evaluation of QRISK cardiovascular risk prediction: a prospective open cohort study. BMJ 2009;339:b2584.

8. Armitage J, Bowman L, Wallendszus K, et al. Collins R Study of the Effectiveness of Additional Reductions in Cholesterol and Homocysteine (SEARCH) Collaborative Group. Intensive lowering of LDL cholesterol with $80 \mathrm{mg}$ versus $20 \mathrm{mg}$ simvastatin daily in 12, 064 survivors of myocardial infarction: a double-blind randomised trial. Lancet 2010;376:1658-69.

9. NHS Employers and BMA. Quality and Outcomes Framework for 2012/13. Guidance for PCOs and practices, 2012.

10. Roland M, Campbell S. Successes and failures of pay for performance in the United Kingdom. $N$ Engl J Med 2014;370:1944-9.

11. Eijkenaar F, Emmert M, Scheppach M, et al. Effects of pay for performance in health care: a systematic review of systematic reviews. Health Policy 2013;110:115-30.

12. Penning-van Beest FJA, Termorshuizen F, Goettsch WG, et al. Adherence to evidence-based statin guidelines reduces the risk of hospitalizations for acute myocardial infarction by $40 \%$ : a cohort study. Eur Heart J 2007;28:154-9.

13. Kotseva K, Wood D, De Backer GD, et al. EUROASPIRE III: a survey on the lifestyle, risk factors and use of cardioprotective drug therapies in coronary patients from 22 European countries. Eur J Cardiovasc Prev Rehabil 2009;16:121-37.

14. Hippisley-Cox J, Pringle M, Crown N, et al. Sex inequalities in ischaemic heart disease in general practice: cross sectional survey. BMJ 2001:322:832.

15. Millett C, Gray J, Wall M, et al. Ethnic disparities in coronary heart disease management and pay for performance in the UK. J Gen Intern Med 2009;24:8-13.

16. Secretary of State for Health. Health Inequalities: working together to reduce health inequalities and meet new duties (Letter). Department of Health, 2015. 31-3-0015. https://www.gov.uk/ government/uploads/system/uploads/attachment_data/file/286551/ SofS letter health inequalities.pdf
17. Health and Social Care Act 2012. 2015. The Stationary Office. 4-7-2015. http://www.legislation.gov.uk/ukpga/2012/7/contents/ enacted

18. Health and Social Care Information Centre. Quality and Outcomes Framework 2012-13. 2015. 31-3-0015. http://www.hscic.gov.uk/ catalogue/PUB12262

19. Stata Statistical Software: Release 13. [computer program]. Version 13. College Station, TX: StataCorp LP., 2013.

20. Goldstein H. Multilevel statistical models. 922 edn. John Wiley \& Sons, 2011.

21. Karalis DG, Subramanya RD, Hessen SE, et al. Achieving optimal lipid goals in patients with coronary artery disease. Am J Cardiol 2011;107:886-90.

22. Kauffman $\mathrm{AB}$, Olson $\mathrm{KL}$, Youngblood $\mathrm{ML}$, et al. Attainment of low-density lipoprotein cholesterol goals in coronary artery disease. J Clin Lipidol 2010;4:173-80.

23. Reibis RK, Bestehorn K, Pittrow D, et al. Elevated risk profile of women in secondary prevention of coronary artery disease: A 6-year survey of 117,913 patients. J Womens Health (Larchmt) 2009;18:1123-31.

24. Singh M, Chin SH, Crothers D, et al. Time trends of gender-based differences in lipid goal attainments during secondary prevention of coronary artery disease: results of a 5-year survey. Am $J$ Ther 2013;20:613-17.

25. Victor BM, Teal V, Ahedor L, et al. Gender differences in achieving optimal lipid goals in patients with coronary artery disease. Am J Cardiol 2014;113:1611-15.

26. Giralt D, Domingues-Montanari S, Mendioroz M, et al. The gender gap in stroke: a meta-analysis. Acta Neurol Scand 2012;125:83-90.

27. Simpson CR, Wilson $\mathrm{C}$, Hannaford PC, et al. Evidence for age and sex differences in the secondary prevention of stroke in Scottish primary care. Stroke 2005;36:1771-5.

28. Bugiardini R, Navarro Estrada JL, Nikus K, et al. Gender bias in acute coronary syndromes. Curr Vasc Pharmacol 2010;8:276-84.

29. Williams D, Bennett K, Feely J. Evidence for an age and gender bias in the secondary prevention of ischaemic heart disease in primary care. Br J Clin Pharmacol 2003;55:604-8.

30. Buja A, Boemo DG, Furlan $P$, et al. Tackling inequalities: are secondary prevention therapies for reducing post-infarction mortality used without disparities? Eur J Prev Cardiol 2014;21:222-30.

31. Lawesson SS, Alfredsson J, Fredrikson M, et al. Time trends in STEMI-improved treatment and outcome but still a gender gap: a prospective observational cohort study from the SWEDEHEART register. BMJ Open 2012;2:e000726.

32. Hawkins NM, Scholes S, Bajekal M, et al. The UK National Health Service: delivering equitable treatment across the spectrum of coronary disease. Circ Cardiovasc Qual Outcomes 2013:6:208-16.

33. Koopman C, Vaartjes I, Heintjes EM, et al. Persisting gender differences and attenuating age differences in cardiovascular drug use for prevention and treatment of coronary heart disease, 19982010. Eur Heart J 2013;34:3198-205.

34. Mathur R, Badrick E, Boomla K, et al. Prescribing in general practice for people with coronary heart disease; equity by age, sex, ethnic group and deprivation. Ethn Health 2011;16:107-23.

35. Saposnik G, Goodman SG, Leiter LA, et al. Applying the evidence: do patients with stroke, coronary artery disease, or both achieve similar treatment goals? Stroke 2009;40:1417-24.

36. Hawkins NM, Scholes S, Bajekal M, et al. Reducing socioeconomic inequality in coronary disease treatments: the NHS finally triumphs? J Epidemiol Community Health 2011;65(Suppl 2): A20-1.

37. Reid FDA, Cook DG, Whincup PH. Use of statins in the secondary prevention of coronary heart disease: is treatment equitable? Heart 2002;88:15-19.

38. DeWilde S, Carey IM, Bremner SA, et al. Evolution of statin prescribing 1994-2001: a case of agism but not of sexism? Heart 2003;89:417-21.

39. Carey IM, DeWilde S, Shah SM, et al. Statin use after first myocardial infarction in UK men and women from 1997 to 2006: Who started and who continued treatment? Nutr Metab Cardiovasc Dis 2012;22:400-8.

40. Boeckxstaens P, Smedt DD, Maeseneer JD, et al. The equity dimension in evaluations of the quality and outcomes framework: a systematic review. BMC Health Serv Res 2011;11:209.

41. Walford H, Kearns B, Barron S. Technical briefing: prevalence modelling. Association of Public Health Observatories, 2011.

42. McGinn D, Godman B, Lonsdale J, et al. Initiatives to enhance the quality and efficiency of statin and PPI prescribing in the UK: impact and implications. Expert Rev Pharmacoecon Outcomes Res 2010;10:73-85. 